\title{
Clustering of Lifestyle Factors and Its Association with Low Back Pain: A Cross-Sectional Study of Over 400,000 Japanese Adults
}

This article was published in the following Dove Press journal:

Journal of Pain Research

\author{
Takahiko Yoshimoto (D) \\ Hirotaka Ochiai $\mathbb{D}^{\prime}$ \\ Takako Shirasawa (D) \\ Satsue Nagahama ${ }^{2}$ \\ Akihito Uehara' \\ Jun Muramatsu' \\ Akatsuki Kokaze (D) \\ 'Department of Hygiene, Public Health \\ and Preventive Medicine, Showa \\ University School of Medicine, \\ Shinagawa-Ku, Tokyo, Japan; ${ }^{2}$ All Japan \\ Labor Welfare Foundation, Shinagawa-Ku, \\ Tokyo, Japan
}

Purpose: Although many studies have indicated the association between low back pain (LBP) and lifestyle factors, the combined effect of lifestyle factors on LBP has not been adequately investigated. We aimed to investigate the association between a cluster of unhealthy lifestyle behaviors and LBP using a large cohort of Japanese adults.

Methods: We included 419,003 adults aged over 20 years who underwent an annual health checkup between April 2013 and March 2014 in Japan. Information on the following lifestyle factors was collected using the standardized questionnaire: smoking, alcohol intake, exercise, physical activity, walking speed, weight control, eating habits, and sleep. Each factor was evaluated as a dichotomous variable (1: health risk, 0: no health risk). A lifestyle risk score was calculated by summing the score of each lifestyle factor (range: 0-12) and was categorized into three groups (low, moderate, high). LBP was defined as self-reported LBP under treatment. Logistic regression analysis was conducted to calculate the odds ratio (OR) and 95\% confidence interval (CI) for LBP.

Results: In multivariable logistic regression analysis, the OR for LBP was significantly higher in the moderate-risk score group (adjusted OR: 1.33 [95\% CI: 1.23-1.44] in men; 1.40 [95\% CI: 1.27-1.54] in women) and the high-risk score group (adjusted OR: 1.54 [95\% CI: 1.43-1.67] in men; 1.83 [95\% CI: 1.64-2.03] in women) than in the low-risk score group. A trend of higher risk of LBP associated with higher lifestyle risk score was observed in both sexes ( $p$ for trend < $0.001)$. These results were similar even in subgroup analysis by age and body mass index (BMI). Conclusion: Clustering of unhealthy lifestyles was associated with increased risk of LBP regardless of age and BMI. These results may provide implications for better prevention and management of LBP, considering modifiable lifestyle factors.

Keywords: lifestyle, low back pain, clustering, health checkup

\section{Introduction}

Low back pain (LBP) is one of the primary causes of disability and remains a major health problem worldwide. ${ }^{1}$ LBP has an enormous economic burden including direct and indirect costs such as loss of work productivity. ${ }^{2}$ Previous epidemiological studies have indicated a number of multidimensional risk factors for LBP. ${ }^{3}$ Among these, lifestyle factors are a particularly important domain as they are potentially modifiable. In fact, targeting lifestyle as part of the management of LBP has been recommended. ${ }^{4,5}$

The impact of lifestyle factors such as smoking, physical activity, alcohol, and diet on health outcome has been extensively studied. This impact, mainly on
Correspondence: Takahiko Yoshimoto Email yoshimotot@med.showa-u.ac.jp
Journal of Pain Research 2020:13 |4||-1419

| 4 | | 
cardiovascular disease,${ }^{6}$ diabetes, ${ }^{7}$ cancer, ${ }^{8}$ and mortality, ${ }^{9}$ has been shown to be especially greater when the factors were accumulated. Therefore, evaluating the cluster of lifestyle factors is considered important to prevent the negative effects on health.

The development and chronicity of LBP have been considered to be linked to lifestyle factors. A populationbased study using data from National Health and Nutrition Examination Survey indicated that smoking, physical activity, and obesity were associated with LBP. ${ }^{10}$ Similarly, many studies investigated the association of LBP with each lifestyle factor such as smoking, physical inactivity, alcohol consumption, and sleep disturbance. ${ }^{11-14}$ However, the combined effects of lifestyle risk factors on LBP have not been adequately investigated. In particular, studies for Asian population who has a bit different lifestyle from Western population are very scarce. Elucidating the effect of the accumulation of lifestyle factors on LBP may help to demonstrate the importance of lifestyle modification for the prevention or management of LBP. Therefore, we investigated the association between the clustering of multiple lifestyle factors and LBP using a large-scale, crosssectional data in Japan as the primary objective. Moreover, if the association was found, we evaluated the effects of age and body mass index (BMI) on the association. We hypothesized that the accumulation of unhealthy lifestyle factors is associated with increased risk of LBP because lifestyle behaviors consist of multiple dimensions that coexist and are mutually related in many cases. ${ }^{15,16}$

\section{Methods}

\section{Study Population}

This was a cross-sectional study that used health checkup data. The check-up was conducted by the All Japan Labor Welfare Foundation, a health checkup center in Japan. A health checkup is mandatory for all employees in Japan at least once a year under the Industrial Safety and Health Act. Subjects were almost Japanese workers but included a small number of their dependents and foreign workers. Eligible subjects in the present study were adults aged over 20 years who underwent the annual health checkup between April 2013 and March 2014. Of the 552,005 subjects, 551,871 subjects consented to participate in this study. Of these, we excluded 132,868 subjects with missing data on any variables used in the present study. Thus, 419,003 participants were included in the analysis. Written informed consent for the use of personal health checkup data in this study was obtained from each participant. This study protocol was approved by the Ethics Committee of the All Japan Labor Welfare Foundation (Approval No. 9-1-0007) and the medical ethics committee of Showa University School of Medicine (Approval No. 2407).

\section{Study Measures}

Data on age, sex, lifestyle behaviors, medical history, and current use of medications were collected using a selfadministered questionnaire. Trained staff measured height to the nearest $0.1 \mathrm{~cm}$ using a stadiometer and weight to the nearest $0.1 \mathrm{~kg}$ using a scale. BMI was calculated as weight $(\mathrm{kg})$ divided by the square of height $(\mathrm{m})$. Blood pressure was measured in the sitting position using an automated sphygmomanometer (HEM-907, Omron, Kyoto, Japan). LBP was defined as self-reported LBP under treatment (ie, a "yes" answer to the question "Do you have LBP under treatment including follow-up?"). ${ }^{17}$

Blood samples were collected and stored in a cooler at $4^{\circ} \mathrm{C}$ for transporting to an external laboratory (SRL, Tokyo, Japan). Triglyceride levels were measured using an enzymatic method (AU5400; Beckman Coulter, Tokyo, Japan), while low-density lipoprotein cholesterol (LDL-C) and high-density lipoprotein cholesterol (HDL-C) were measured using a direct method (AU5400; Beckman Coulter, Tokyo, Japan). Hemoglobin A1c (HbA1c) level was determined using latex agglutination turbidimetry (JCA-BM9130, JEOL, Tokyo, Japan).

Hypertension was defined as systolic blood pressure $\geq$ $140 \mathrm{mmHg}$, diastolic blood pressure $\geq 90 \mathrm{mmHg}$, or medication use for hypertension. ${ }^{18}$ Diabetes was defined as HbAlc (National Glycohemoglobin Standardization Program) $\geq$ $6.5 \%$ or medication use for diabetes. ${ }^{19}$ Dyslipidemia was defined as triglyceride $\geq 150 \mathrm{mg} / \mathrm{dL}$, HDL-C $<40 \mathrm{mg} / \mathrm{dL}$, LDL-C $\geq 140 \mathrm{mg} / \mathrm{dL}$, or medication use for dyslipidemia. ${ }^{20}$

\section{Assessment of Lifestyle Risk Score}

Questionnaire items on lifestyle behaviors were based on the standardized questionnaire used for the National Health Promotion Program, ${ }^{21,22}$ which started in Japan in 2008 and aimed to prevent lifestyle-related diseases (eg, metabolic syndrome and cardiovascular disease). The following 12 items related to lifestyle behaviors were used in the present study: 1) smoking habits (current, former, none), 2) alcohol intake (everyday, sometimes, none), 3) exercise $\geq 30 \mathrm{~min} /$ day, $\geq$ twice a week, and $\geq 1$ year (yes, no), 4) physical activity equal to walking $\geq 60 \mathrm{~min} /$ day 
(yes, no), 5) walking faster than others in the same generation (yes, no), 6) weight gain $\geq 10 \mathrm{~kg}$ since age 20 years (yes, no), 7) body weight change $\geq 3 \mathrm{~kg}$ during the preceding 1 year (yes, no), 8) eating speed (fast, normal, slow), 9) eating dinner within 2 hours before bed $\geq$ three times per week (yes, no), 10) having a snack after dinner $\geq$ three times per week (yes, no), 11) skipping breakfast $\geq$ three times per week (yes, no), and 12) adequate sleeping (yes, no).

For each lifestyle factor, we created a binary variable; 1 represented health risk (unhealthy) and 0 showed no health risk. The criteria of health risk were determined with reference to the recommended guideline or current health-related studies. ${ }^{7,23-29}$ Specifically, we assigned a score of 1 for each item as follows: 1) current smoking, 2) drinking alcohol every day, 3-5) a response of no, 6-7) yes, 8) eating fast, 9-11) yes, and 12) no response. A lifestyle risk score was calculated by combining the scores of the 12 lifestyle factors (range: $0-12)^{19}$ and was categorized into the following three groups by tertile of the total score; low (score: 0-3), moderate (4-5), and high risk (6-12).

\section{Statistical Analysis}

Data on the participants' characteristics are presented as n (\%), or median (25th, 75th percentiles) and mean (standard deviation). Characteristics of the study participants with and without LBP were compared using chi-squared test for categorical variables or Wilcoxon rank-sum test for continuous variables.

To evaluate the association between LBP and lifestyle risk levels, a logistic regression analysis was performed to calculate the odds ratio (OR) and $95 \%$ confidence interval (CI) for LBP. Model 1 was a crude model, and model 2 was adjusted for age and BMI (as continuous variables). Model 3 was further adjusted for hypertension, diabetes, and dyslipidemia (as dichotomous variables). We then examined the association between LBP and lifestyle risk score stratified by age (20-39, 40-59, and $\geq 60$ years) and BMI (underweight: $<18.5$, normal weight: 18.5-24.9, and overweight/obesity: $\geq 25 \mathrm{~kg} / \mathrm{m}^{2}$ ) categories in model 3. Multiple co-linearity was not suspected in the analysis, with all variance inflation factors (VIFs) were $<2$. Test for trend was conducted with the lifestyle risk score groups considered as continuous variables. All statistical analyses were performed using SAS software version 9.4 (SAS Institute Inc., Cary, NC,
USA). A $p$ value $<0.05$ was considered statistically significant.

\section{Results}

The median age (25th, 75th percentile) of the study participants was 45 (range, 36, 55) years, and 67.1\% of the participants were men. The prevalence of LBP under treatment was almost $2 \%(n=8061)$ of the total population. Comparison of the participants' characteristics according to LBP is shown in Table 1 for men and Table 2 for women. Individuals with LBP were older, had higher BMI, and were more likely to have hypertension, diabetes, and dyslipidemia than those without LBP in both sexes.

Table 3 shows the association between lifestyle risk score (low, moderate, and high) and LBP by sex. In both sexes, the age- and BMI-adjusted OR for LBP were higher in the moderate risk score group (OR: 1.32 [95\% CI: 1.22-1.43] in men; OR: 1.39 [95\% CI: 1.27-1.54] in women) and the high-risk score group (OR: $1.53[95 \%$ CI: 1.42-1.65] in men; OR: 1.81 [95\% CI: 1.63-2.02] in women) compared with those in the low-risk score group. Further adjustment for hypertension, diabetes, and dyslipidemia did not markedly change the association of LBP with the lifestyle risk score.

Table 4 shows the association between LBP and lifestyle risk score by age groups. In all age categories, compared to individuals with low-risk score, the ORs for LBP in the moderate and the high-risk score groups were significantly increased. A trend of higher risk of LBP associated with higher lifestyle risk score was observed in both sexes and all age groups ( $p$ for trend $<0.001$ in all).

We also performed BMI-stratified analysis for the association between lifestyle risk score and LBP (Table 5). Among underweight men, only the high-risk score group showed higher OR for LBP (adjusted OR: 1.66 [95\% CI: 1.15-2.38]). Meanwhile, among underweight women, higher ORs for LBP were observed in the moderate risk score group (adjusted OR: 1.43 [95\% CI: 1.05-1.95]) and the high-risk score group (adjusted OR: 1.68 [95\% CI: 1.13-2.50]). Among subjects with normal weight or overweight/obesity, LBP was significantly associated with lifestyle risk score in the moderate risk score group and the high-risk score group. There were significant doseresponse relationships between the level of lifestyle risk score and LBP in all BMI strata ( $p$ for trend $<0.01$ in all). 
Table I Characteristics of the Study Participants by Low Back Pain in Men

\begin{tabular}{|c|c|c|c|}
\hline & \multirow{2}{*}{$\begin{array}{l}\text { Low Back Pain (+) } \\
(n=5486)\end{array}$} & \multirow{2}{*}{$\begin{array}{l}\text { Low Back Pain }(-) \\
(n=275,622)\end{array}$} & \multirow[t]{2}{*}{ p-value ${ }^{a}$} \\
\hline & & & \\
\hline \multicolumn{4}{|l|}{ Age, years } \\
\hline Median (25th, 75th percentiles) & $5 I(4 I, 6 I)$ & $45(36,55)$ & $<0.001$ \\
\hline Mean (standard deviation) & $50.9(12.5)$ & $45.5(12.5)$ & \\
\hline \multicolumn{4}{|l|}{ Body mass index, $\mathrm{kg} / \mathrm{m}^{2}$} \\
\hline Median (25th, 75th percentiles) & $23.7(21.6,26.0)$ & $23.2(21.1,25.6)$ & $<0.001$ \\
\hline Mean (standard deviation) & $24.1(3.7)$ & $23.7(3.7)$ & \\
\hline Current smoker, n (\%) & $2431(44.3)$ & $129,977(47.2)$ & $<0.001$ \\
\hline Daily drinker, n (\%) & $2257(4 I . I)$ & $99,315(36.0)$ & $<0.001$ \\
\hline Weight gain ( $\geq 10 \mathrm{~kg}$ since age 20 years), $\mathrm{n}(\%)$ & $2474(45.1)$ & $|06,93|(38.8)$ & $<0.001$ \\
\hline Exercise ( $\geq 30 \mathrm{~min} /$ day, $\geq$ twice/week), n (\%) & $1320(24.1)$ & $64,772(23.5)$ & 0.332 \\
\hline Physical activity ( $\geq$ I hr/day), n (\%) & $2066(37.7)$ & $108,597(39.4)$ & 0.009 \\
\hline Walking faster, $\mathrm{n}(\%)$ & $2289(41.7)$ & $|25||| \mid,(45.4)$ & $<0.001$ \\
\hline Body weight change ( $\geq 3$ kg/year), n (\%) & $2102(38.3)$ & $93,583(34.0)$ & $<0.001$ \\
\hline Eating fast, n (\%) & $1773(32.3)$ & $83,972(30.5)$ & 0.003 \\
\hline Eating dinner within 2 hours before bedtime ( $\geq 3$ times/week), n (\%) & $2294(41.8)$ & $117,739(42.7)$ & 0.181 \\
\hline Having a snack after dinner ( $\geq 3$ times/week), n (\%) & $857(15.6)$ & $42,229(15.3)$ & 0.541 \\
\hline Skipping breakfast ( $\geq 3$ times/week), n (\%) & $1215(22.2)$ & $79,135(28.7)$ & $<0.001$ \\
\hline Adequate sleep, $\mathrm{n}(\%)$ & $2850(52.0)$ & $169,996(61.7)$ & $<0.001$ \\
\hline Hypertension, n (\%) & $1892(34.5)$ & $88,180(32.0)$ & $<0.001$ \\
\hline Diabetes, n (\%) & $488(8.9)$ & $|8,5| \mid(6.7)$ & $<0.001$ \\
\hline Dyslipidemia, n (\%) & $2790(50.9)$ & $136,124(49.4)$ & 0.031 \\
\hline
\end{tabular}

Note: ${ }^{\mathrm{p}} \mathrm{p}$-value based on a chi-squared test or Wilcoxon rank-sum test.

\section{Discussion}

We previously revealed the relationship of metabolic syndrome with LBP among middle-aged Japanese adults. ${ }^{30}$ However, individual components of metabolic syndrome are significantly affected by various lifestyles. In the present study, we investigated the association between the clustering of multiple unhealthy lifestyle behaviors and LBP among all adults using a large-scale health checkup data in Japan. We found that a combination of unhealthy lifestyle behaviors was dose-dependently associated with increased risk of LBP in both sexes. These associations were observed regardless of age and BMI status. To our knowledge, this is the first study demonstrating the influence of unhealthy lifestyle clustering, which included multifaceted lifestyle factors, on LBP in Japanese adults.

In this study, focusing on the clustering of multiple lifestyle risk factors, we evaluated unhealthy lifestyle factors using 12 questionnaire items that have been recommended for use by the National Health Promotion Program in Japan. ${ }^{21,22}$ These factors included Breslow's health habits including smoking, alcohol drinking, physical activity, weight control, breakfast, snacking, and sleep. ${ }^{31}$
Previous studies investigated the relationship between healthy lifestyle behaviors and LBP using a limited number of lifestyle factors, ${ }^{32-34}$ and indicated that health lifestyle behaviors may decrease the risk of developing LBP, although there may be sex- or age-related differences in the effects. It is difficult to directly compare our results with previous findings because the definition of health lifestyle behaviors varies by studies. For example, a previous study defined health behavior using information on BMI, physical exercise, and smoking. ${ }^{33}$ However, our findings were consistent with those of previous studies. Our results that clustering of unhealthy lifestyles could negatively influence LBP may have important implications for the prevention and management of LBP both in a public health and a clinical perspective.

Age is one of the common risk factors for LBP. A previous systematic review has demonstrated that the prevalence of severe LBP increases with age. ${ }^{35}$ Although several lifestyle behaviors were also expected to vary depending on age, our age-stratified analyses indicated the dose-response relationship between accumulation of unhealthy lifestyle risk and LBP regardless of age groups 
Table 2 Characteristics of the Study Participants by Low Back Pain in Women

\begin{tabular}{|c|c|c|c|}
\hline & \multirow{2}{*}{$\begin{array}{l}\text { Low Back Pain (+) } \\
(n=2575)\end{array}$} & \multirow{2}{*}{$\begin{array}{l}\text { Low Back Pain (-) } \\
(\mathrm{n}=135,320)\end{array}$} & \multirow[t]{2}{*}{ p-value ${ }^{a}$} \\
\hline & & & \\
\hline \multicolumn{4}{|l|}{ Age, years } \\
\hline Median (25th, 75th percentiles) & $54(44,61)$ & $46(36,55)$ & $<0.001$ \\
\hline Mean (standard deviation) & $52.3(12.2)$ & $45.6(12.5)$ & \\
\hline \multicolumn{4}{|l|}{ Body mass index, $\mathrm{kg} / \mathrm{m}^{2}$} \\
\hline Median (25th, 75th percentiles) & $22.6(20.4,25.4)$ & $21.5(19.5,24.1)$ & $<0.001$ \\
\hline Mean (standard deviation) & $23.3(4.2)$ & $22.2(3.9)$ & \\
\hline Current smoker, n (\%) & $552(21.4)$ & $26,429(19.5)$ & 0.016 \\
\hline Daily drinker, n (\%) & $384(14.9)$ & $|8,21|(13.5)$ & 0.032 \\
\hline Weight gain ( $\geq 10 \mathrm{~kg}$ since age 20 years), $\mathrm{n}(\%)$ & $880(34.2)$ & $32,|4|(23.8)$ & $<0.001$ \\
\hline Exercise ( $\geq 30 \mathrm{~min} /$ day, $\geq$ twice/week), n (\%) & $494(19.2)$ & $20,391(15.1)$ & $<0.001$ \\
\hline Physical activity ( $\geq$ I hr/day), n (\%) & $928(36.0)$ & $44,201(32.7)$ & $<0.001$ \\
\hline Walking faster, n (\%) & $926(36.0)$ & $52,7 \mid I(39.0)$ & 0.002 \\
\hline Body weight change ( $\geq 3$ kg/year), n (\%) & $907(35.2)$ & $39,699(29.3)$ & $<0.001$ \\
\hline Eating fast, $\mathrm{n}(\%)$ & $687(26.7)$ & $30,257(22.4)$ & $<0.001$ \\
\hline Eating dinner within 2 hours before bedtime ( $\geq 3$ times/week), n (\%) & $690(26.8)$ & $33,694(24.9)$ & 0.028 \\
\hline Having a snack after dinner ( $\geq 3$ times/week), n (\%) & $5 I I(19.8)$ & $25,981(19.2)$ & $0.41 \mathrm{I}$ \\
\hline Skipping breakfast ( $\geq 3$ times/week), n (\%) & $464(18.0)$ & $25,878(19.1)$ & 0.158 \\
\hline Adequate sleep, $\mathrm{n}(\%)$ & $1191(46.3)$ & $80,161(59.2)$ & $<0.001$ \\
\hline Hypertension, n (\%) & $689(26.8)$ & $29,679(21.9)$ & $<0.001$ \\
\hline Diabetes, n (\%) & $134(5.2)$ & $4453(3.3)$ & $<0.001$ \\
\hline Dyslipidemia, n (\%) & $1027(39.9)$ & $45,872(33.9)$ & $<0.001$ \\
\hline
\end{tabular}

Note: ${ }^{\mathrm{a}} \mathrm{p}$-value based on a chi-squared test or Wilcoxon rank-sum test.

(20-39, 40-59, and $\geq 60$ years). These findings suggest the importance of education related to healthy lifestyle for preventing LBP throughout the adult population.

Previous systematic reviews with meta-analysis have shown that overweight and obesity increased the risk of LBP. $^{36,37}$ Moreover, many of the unhealthy lifestyle factors included in the present study have been considered to be associated with overweight/obesity. ${ }^{23,24,26,28}$ Therefore, to eliminate the effects of BMI status on LBP, we analyzed the association of LBP with lifestyle risk according to BMI strata (underweight, normal, and overweight/obesity). This stratified analysis showed that

Table 3 Association Between Lifestyle Risk Score and Low Back Pain by Sex

\begin{tabular}{|c|c|c|c|c|c|c|}
\hline & & Total & LBP & Model I & Model 2 & Model 3 \\
\hline & & $\mathbf{N}$ & n (\%) & OR (95\% Cl) & OR (95\% Cl) & OR $(95 \% \mathrm{Cl})$ \\
\hline \multicolumn{7}{|l|}{ Men } \\
\hline Lifestyle risk score & $\begin{array}{l}\text { Low }(0-3) \\
\text { Moderate (4-5) } \\
\text { High }(6-12) \\
p \text { for trend }\end{array}$ & $\begin{array}{l}63,022 \\
105,120 \\
112,966\end{array}$ & $\begin{array}{l}986(1.56) \\
2080(1.98) \\
2420(2.14)\end{array}$ & $\begin{array}{l}1.00 \\
1.27(1.18-1.37) \\
1.38(1.28-1.48) \\
<0.001\end{array}$ & $\begin{array}{l}1.00 \\
1.32(1.22-1.43) \\
1.53(1.42-1.65) \\
<0.001\end{array}$ & $\begin{array}{l}1.00 \\
1.33(1.23-1.44) \\
1.54(1.43-1.67) \\
<0.001\end{array}$ \\
\hline \multicolumn{7}{|l|}{ Women } \\
\hline Lifestyle risk score & $\begin{array}{l}\text { Low }(0-3) \\
\text { Moderate }(4-5) \\
\text { High }(6-12) \\
p \text { for trend }\end{array}$ & $\begin{array}{l}49,179 \\
55,757 \\
32,959\end{array}$ & $\begin{array}{l}735(1.49) \\
1054(1.89) \\
786(2.38)\end{array}$ & $\begin{array}{l}1.00 \\
1.27(1.15-1.40) \\
1.61(1.45-1.78) \\
<0.001\end{array}$ & $\begin{array}{l}1.00 \\
1.39(1.27-1.54) \\
1.81(1.63-2.02) \\
<0.001\end{array}$ & $\begin{array}{l}1.00 \\
1.40(1.27-1.54) \\
1.83(1.64-2.03) \\
<0.001\end{array}$ \\
\hline
\end{tabular}

Notes: Model I: Crude model. Model 2: Adjusted for age and body mass index. Model 3: Adjusted for age, body mass index, hypertension, diabetes, and dyslipidemia. Abbreviations: $\mathrm{OR}$, odds ratio; $\mathrm{Cl}$, confidence interval; LBP, low back pain. 
Table 4 Association Between Lifestyle Risk Score and Low Back Pain Stratified by Age Group

\begin{tabular}{|c|c|c|c|c|c|c|c|c|c|}
\hline & \multicolumn{3}{|c|}{ Age: $20-39$ Years } & \multicolumn{3}{|c|}{ Age: $40-59$ Years } & \multicolumn{3}{|c|}{ Age: $\geq 60$ Years } \\
\hline & Total & LBP & Adjusted & Total & LBP & Adjusted & Total & LBP & Adjusted \\
\hline & $\mathbf{N}$ & n (\%) & OR (95\% CI) & $\mathbf{N}$ & n (\%) & OR (95\% Cl) & $\mathbf{N}$ & n (\%) & OR (95\% CI) \\
\hline \multicolumn{10}{|l|}{ Men } \\
\hline \multicolumn{10}{|l|}{ Lifestyle risk score } \\
\hline Low (0-3) & 20,831 & $166(0.80)$ & 1.00 & 27,222 & 406 (I.49) & 1.00 & 14,969 & $414(2.76)$ & 1.00 \\
\hline Moderate (4-5) & 33,946 & $383(1.13)$ & $1.33(1.11-1.60)$ & 52,474 & $1043(1.99)$ & $1.33(1.19-1.50)$ & 18,700 & $654(3.50)$ & $1.36(1.20-1.54)$ \\
\hline High (6-12) & 39,307 & $558(\mathrm{I} .42)$ & $1.56(1.30-1.86)$ & 61,866 & $1348(2.18)$ & $1.47(1.31-1.65)$ & II,793 & $514(4.36)$ & $1.79(1.56-2.05)$ \\
\hline$p$ for trend & & & $<0.001$ & & & $<0.001$ & & & $<0.001$ \\
\hline \multicolumn{10}{|l|}{ Women } \\
\hline \multicolumn{10}{|l|}{ Lifestyle risk score } \\
\hline Low (0-3) & 13,652 & $87(0.64)$ & 1.00 & 25,086 & $346(1.38)$ & 1.00 & $|0,44|$ & $302(2.89)$ & 1.00 \\
\hline Moderate (4-5) & 18,182 & $158(0.87)$ & 1.31 (I.0I-1.7I) & 29,938 & 573 (1.91) & $1.37(1.20-1.57)$ & 7637 & $323(4.23)$ & $1.54(1.31-1.82)$ \\
\hline High (6-12) & 11,475 & $155(1.35)$ & $1.89(1.44-2.48)$ & 18,404 & $48 I(2.61)$ & $1.84(1.59-2.13)$ & 3080 & $150(4.87)$ & $1.79(1.45-2.21)$ \\
\hline$p$ for trend & & & $<0.001$ & & & $<0.001$ & & & $<0.001$ \\
\hline
\end{tabular}

Note: Adjusted for age, body mass index, hypertension, diabetes, and dyslipidemia.

Abbreviations: $\mathrm{OR}$, odds ratio; $\mathrm{Cl}$, confidence interval; $\mathrm{LBP}$, low back pain.

moderate and high lifestyle risk scores were significantly associated with increased risk of LBP among all individuals except for underweight men. Moreover, regardless of BMI status, the accumulation of unhealthy lifestyle risk factors resulted in a significantly higher OR for LBP ( $p$ for trend $<0.01$ ). These results imply that improving unhealthy lifestyle behaviors may prevent the development of LBP even in non-overweight individuals.
No simple explanation can be given with regard to the potential mechanism behind the association of unhealthy lifestyle clustering with risk of LBP. Unhealthy lifestyle may affect LBP through biological processes such as vascular degeneration. For example, metabolic disturbance caused by unhealthy lifestyle could induce the atherosclerotic change in the artery, which may lead to the degeneration of the lumbar intervertebral disc. ${ }^{38}$ Even individuals without obesity have been indicated to readily

Table 5 Association Between Lifestyle Risk Score and Low Back Pain Stratified by BMI Status

\begin{tabular}{|c|c|c|c|c|c|c|c|c|c|}
\hline & \multicolumn{3}{|c|}{ Underweight (BMI $<18.5 \mathrm{~kg} / \mathrm{m}^{2}$ ) } & \multicolumn{3}{|c|}{ Normal $\left(18.5-24.9 \mathrm{~kg} / \mathrm{m}^{2}\right)$} & \multicolumn{3}{|c|}{ Overweight $/$ Obese $\left(B M I \geq 25 \mathrm{~kg} / \mathrm{m}^{2}\right)$} \\
\hline & Total & LBP & Adjusted & Total & LBP & Adjusted & Total & LBP & Adjusted \\
\hline & $\mathbf{N}$ & n (\%) & OR $(95 \% \mathrm{CI})$ & $\mathbf{N}$ & n (\%) & OR $(95 \% \mathrm{CI})$ & $\mathbf{N}$ & n (\%) & OR $(95 \% \mathrm{CI})$ \\
\hline \multicolumn{10}{|l|}{ Men } \\
\hline \multicolumn{10}{|l|}{ Lifestyle risk score } \\
\hline Low $(0-3)$ & 3833 & $49(1.28)$ & 1.00 & 47,712 & $728(1.53)$ & 1.00 & 11,477 & $209(1.82)$ & 1.00 \\
\hline Moderate (4-5) & 5470 & $74(1.35)$ & $1.07(0.75-1.55)$ & $71,|3|$ & $1336(1.88)$ & $1.32(1.21-1.45)$ & 28,519 & $670(2.35)$ & $1.37(1.17-1.60)$ \\
\hline High $(6-12)$ & 3824 & $78(2.04)$ & $1.66(1.15-2.38)$ & 63,763 & $131 \mid(2.06)$ & $1.60(1.45-1.75)$ & 45,379 & $1031(2.27)$ & $1.46(1.25-1.70)$ \\
\hline$p$ for trend & & & 0.004 & & & $<0.001$ & & & $<0.001$ \\
\hline \multicolumn{10}{|l|}{ Women } \\
\hline \multicolumn{10}{|l|}{ Lifestyle risk score } \\
\hline Low (0-3) & 7561 & $77(1.02)$ & 1.00 & 36,415 & $559(1.54)$ & 1.00 & 5203 & $99(1.90)$ & 1.00 \\
\hline Moderate (4-5) & 7391 & $90(1.22)$ & $1.43(1.05-1.95)$ & 37,478 & 635 (1.69) & $1.28(1.14-1.44)$ & 10,888 & $329(3.02)$ & $1.75(1.39-2.20)$ \\
\hline High $(6-12)$ & 2939 & $38(1.29)$ & $1.68(1.13-2.50)$ & 19,357 & $449(2.32)$ & $1.95(1.7 I-2.22)$ & 10,663 & $299(2.80)$ & $1.80(1.42-2.27)$ \\
\hline$p$ for trend & & & 0.005 & & & $<0.001$ & & & $<0.001$ \\
\hline
\end{tabular}

Note: Adjusted for age, body mass index, hypertension, diabetes, and dyslipidemia.

Abbreviations: OR, odds ratio; $\mathrm{Cl}$, confidence interval; LBP, low back pain; BMI, body mass index. 
develop metabolic disturbances, ${ }^{39}$ which might support our results in the BMI-stratified analysis. The other possible explanation is the involvement of psychological aspects. Several studies have indicated that lifestyle factors are associated with mental health, which may be bidirectional. ${ }^{40,41}$ From a perspective in the biopsychosocial model, unhealthy lifestyle factors may affect the increased risk of LBP through psychological problems. Further, high levels of health literacy have been indicated to be associated with healthy lifestyle. ${ }^{42}$ A previous study has emphasized the importance of addressing the health literacy in the self-management for LBP. ${ }^{43}$ Further investigations are needed with regard to these points.

Our study indicated that the prevalence of LBP under treatment was almost $2 \%$ in total participants. The low prevalence may be due to the definition of LBP used in this study. We used LBP under treatment as the outcome of interest according to a previous study. ${ }^{17}$ The outcome may mean to be individuals with severe or disabling LBP. The Comprehensive Survey of Living Conditions, conducted by the Ministry of Health, Labour and Welfare in Japan, indicated the prevalence of backache under treatment was $5.25 \%$ in which elderly individuals with high prevalence of LBP were included. ${ }^{17}$ Also, a previous study showed that the prevalence of LBP treated was $3.2 \%$ among health examinees aged $40-59$ years, ${ }^{44}$ which was similar to our results.

The strength of this study was the large-scale sample size that helped reduce the random error and could permit exploring the risk along multidimensional aspects of lifestyle factors. However, the present study also has several limitations. First and foremost, the lack of longitudinal data is a shortcoming that prevents us from determining the direction of the links between LBP and the clustering of lifestyles. LBP could have negative effects on healthy lifestyles such as exercise or sleep. Further prospective studies are warranted to establish the causal relationship between the accumulation of unhealthy lifestyles and LBP. Second, the determination of LBP relied on self-reports and was not based on clinical examinations. Differentiating LBP type (eg, acute pain or chronic pain, or localized pain or radicular pain, disease-specific) might have been helpful to explore the associations found here in more detail. Third, we performed analyses assuming that there is no interaction between each lifestyle factor in this study. Although we used the same methods as a previous study, ${ }^{19}$ it will be necessary to assess the interaction between lifestyle factors for accurately estimating the combined effects of lifestyles on LBP in future studies. Fourth, we cannot rule out the effects of unmeasured confounders (eg, occupation type, contents of diet, education level, or psychological status). ${ }^{3}$ In addition, although participants in this study were almost workers, we could not obtain work-related information such as type of the industry, working time, and shift pattern. This might limit the generalizability of our results. Finally, we evaluated information on lifestyle factors using a self-reported questionnaire, which is prone to social desirability bias. This could lead to misclassification of exposure; the misclassification is considered non-differential in its nature, which may have resulted in dilution of a true association.

\section{Conclusions}

In summary, we investigated the combined effects of multiple unhealthy lifestyle behaviors on LBP among more than 400,000 Japanese adults. Our results indicated that the accumulation of unhealthy lifestyle factors was associated with increased risk of LBP, and this was consistent across age and BMI status. These findings may provide important implications for the better prevention and management of LBP considering modifiable lifestyle factors.

\section{Data Sharing Statement}

The data used in the current study are available on reasonable request and with permission of the Ethics Committee of the All Japan Labor Welfare Foundation.

\section{Ethics Approval and Informed Consent}

The present study was approved by the medical ethics committee of Showa University School of Medicine (Approval No. 2407) and the Ethics Committee of the All Japan Labor Welfare Foundation (Approval No. 9-1-0007). Written informed consent was obtained from each subject.

\section{Acknowledgments}

The authors thank Dr. Nobuo Yanagisawa, Dr. Takeshi Kawaguchi, Mr. Takahiro Tamura and Mr. Yutaka Hoshina in the All Japan Labor Welfare Foundation for their support.

\section{Funding}

This study was supported in part by the Grant-in-Aid for Young Scientists (JP18K17979) from the Ministry of 
Education, Culture, Sports, Science, and Technology of Japan.

\section{Disclosure}

The authors declare that they have no competing interests.

\section{References}

1. GBD. 2017 Disease and Injury Incidence and Prevalence Collaborators. Global, regional, and national incidence, prevalence, and years lived with disability for 354 diseases and injuries for 195 countries and territories, 1990-2017: a systematic analysis for the global burden of disease study 2017. Lancet. 2018;392(101 59):1789-1858. doi:10.1016/S0140-6736(18)32279-7

2. Loeppke R, Taitel M, Richling D, et al. Health and productivity as a business strategy. J Occup Environ Med. 2007;49(7):712-721. doi:10.1097/JOM.0b013e318133a4be

3. Krismer M, van Tulder M. Strategies for prevention and management of musculoskeletal conditions. Low back pain (non-specific). Best Pract Res Clin Rheumatol. 2007;21(1):77-91. doi:10.1016/j.berh.20 06.08 .004

4. Wai EK, Rodriguez S, Dagenais S, Hall H. Evidence-informed management of chronic low back pain with physical activity, smoking cessation, and weight loss. Spine J. 2008;8(1):195-202. doi:10.1016/ j.spinee.2007.10.024

5. Dean E, Soderlund A. What is the role of lifestyle behaviour change associated with non-communicable disease risk in managing musculoskeletal health conditions with special reference to chronic pain? BMC Musculoskelet Disord. 2015;16(1):87. doi:10.1186/s12891-0150545-y

6. Kurth T, Moore SC, Gaziano JM, et al. Healthy lifestyle and the risk of stroke in women. Arch Intern Med. 2006;166(13):1403-1409. doi:10.1001/archinte.166.13.1403

7. Hu FB, Manson JE, Stampfer MJ, et al. Diet, lifestyle, and the risk of type 2 diabetes mellitus in women. $N$ Engl J Med. 2001;345 (11):790-797. doi:10.1056/NEJMoa010492

8. Aleksandrova K, Pischon T, Jenab M, et al. Combined impact of healthy lifestyle factors on colorectal cancer: a large European cohort study. BMC Med. 2014;12(1):168. doi:10.1186/s12916-014-0168-4

9. van Dam RM, Li T, Spiegelman D, Franco OH, Hu FB. Combined impact of lifestyle factors on mortality: prospective cohort study in US women. BMJ. 2008;337(sep16 2):a1440. doi:10.1136/bmj.a1440

10. Smuck M, Kao MC, Brar N, Martinez-Ith A, Choi J, Tomkins-Lane CC. Does physical activity influence the relationship between low back pain and obesity? Spine J. 2014;14(2):209-216. doi:10.1016/j. spinee.2013.11.010

11. Yang H, Haldeman S. Behavior-related factors associated with low back pain in the US adult population. Spine (Phila Pa 1976). 2018;43 (1):28-34. doi:10.1097/BRS.0000000000001665

12. Ferreira PH, Pinheiro MB, Machado GC, Ferreira ML. Is alcohol intake associated with low back pain? A systematic review of observational studies. Man Ther. 2013;18(3):183-190. doi:10.1016/j. math.2012.10.007

13. Shiri R, Falah-Hassani K. Does leisure time physical activity protect against low back pain? Systematic review and meta-analysis of 36 prospective cohort studies. Br J Sports Med. 2017;51(19):1410-1418. doi:10.1136/bjsports-2016-097352

14. Shiri R, Karppinen J, Leino-Arjas P, Solovieva S, Viikari-Juntura E. The association between smoking and low back pain: a meta-analysis. Am J Med. 2010;123(1):87 e87-35. doi:10.1016/j. amjmed.2009.05.028

15. Schuit AJ, van Loon AJ, Tijhuis M, Ocke M. Clustering of lifestyle risk factors in a general adult population. Prev Med. 2002;35 (3):219-224. doi:10.1006/pmed.2002.1064
16. Kaczynski AT, Manske SR, Mannell RC, Grewal K. Smoking and physical activity: a systematic review. Am J Health Behav. 2008;32 (1):93-110. doi:10.5993/AJHB.32.1.9

17. Myojin T, Ojima T, Kikuchi K, et al. Orthopedic, ophthalmic, and psychiatric diseases primarily affect activity limitation for Japanese males and females: based on the comprehensive survey of living conditions. J Epidemiol. 2017;27(2):75-79. doi:10.1016/j.je.2016.09. 007

18. Shimamoto K, Ando K, Fujita T, et al. The Japanese society of hypertension guidelines for the management of hypertension (JSH 2014). Hypertens Res. 2014;37(4):253-390.

19. Tada H, Kawashiri MA, Yasuda K, Yamagishi M. Associations between questionnaires on lifestyle and atherosclerotic cardiovascular disease in a Japanese general population: A cross-sectional study. PLoS One. 2018;13(11):e0208135. doi:10.1371/journal.pone.0208135

20. Teramoto T, Sasaki J, Ishibashi S, et al. Executive summary of the Japan Atherosclerosis Society (JAS) guidelines for the diagnosis and prevention of atherosclerotic cardiovascular diseases in Japan -2012 version. J Atheroscler Thromb. 2013;20(6):517-523. doi:10.5551/ jat. 15792

21. Ministry of Health, Labour and Welfare. Standard questionnaire of specific health checkups; 2018. Available from: http://www.mhlw.go. jp/file/06-Seisakujouhou-10900000-Kenkoukyoku/13_44.pdf.

Accessed Jan 20, 2020.

22. Kohro T, Furui Y, Mitsutake N, et al. The Japanese national health screening and intervention program aimed at preventing worsening of the metabolic syndrome. Int Heart J. 2008;49(2):193-203. doi:10. 1536/ihj.49.193

23. Joint WHO/FAO Expert Consultation. Diet, nutrition and the prevention of chronic diseases. World Health Organ Tech Rep Ser. 2003;9161-149.

24. Horikawa C, Kodama S, Yachi Y, et al. Skipping breakfast and prevalence of overweight and obesity in Asian and Pacific regions: a meta-analysis. Prev Med. 2011;53(4-5):260-267. doi:10.1016/j. ypmed.2011.08.030

25. Manson JE, Hu FB, Rich-Edwards JW, et al. A prospective study of walking as compared with vigorous exercise in the prevention of coronary heart disease in women. $N$ Engl J Med. 1999;341 (9):650-658. doi:10.1056/NEJM199908263410904

26. Maruyama K, Sato S, Ohira T, et al. The joint impact on being overweight of self reported behaviours of eating quickly and eating until full: cross sectional survey. BMJ. 2008;337(oct21 2):a2002. doi:10.1136/bmj.a2002

27. Michishita R, Matsuda T, Kawakami S, et al. Long-term body weight gain after maturity is associated with the incidence of chronic kidney disease (CKD), Independent of current body weight, in middle-aged and older men. J Epidemiol. 2019;29(6):213-219. doi:10.2188/jea.JE20170304

28. Okada C, Imano H, Muraki I, Yamada K, Iso H. The association of having a late dinner or bedtime snack and skipping breakfast with overweight in japanese women. J Obes. 2019;2019:2439571. doi: $10.1155 / 2019 / 2439571$

29. Wakasugi M, Kazama JJ, Narita I, et al. Association between combined lifestyle factors and non-restorative sleep in Japan: a cross-sectional study based on a Japanese health database. PLoS One. 2014;9(9):e108718. doi:10.1371/journal.pone.0108718

30. Yoshimoto T, Ochiai H, Shirasawa T, et al. Sex differences in the association of metabolic syndrome with low back pain among middle-aged Japanese adults: a large-scale cross-sectional study. Biol Sex Differ. 2019;10(1):33. doi:10.1186/s13293-019-0249-3

31. Belloc NB, Breslow L. Relationship of physical health status and health practices. Prev Med. 1972;1(3):409-421. doi:10.1016/00917435(72)90014-X

32. Pronk NP, Lowry M, Kottke TE, Austin E, Gallagher J, Katz A. The association between optimal lifestyle adherence and short-term incidence of chronic conditions among employees. Popul Health Manag. 2010;13(6):289-295. doi:10.1089/pop.2009.0075 
33. Miranda H, Viikari-Juntura E, Punnett L, Riihimaki H. Occupational loading, health behavior and sleep disturbance as predictors of low-back pain. Scand J Work Environ Health. 2008;34(6):411-419. doi:10.5271/sjweh. 1290

34. Bohman T, Alfredsson L, Jensen I, Hallqvist J, Vingard E, Skillgate E. Does a healthy lifestyle behaviour influence the prognosis of low back pain among men and women in a general population? A population-based cohort study. BMJ Open. 2014;4(12): e005713. doi:10.1136/bmjopen-2014-005713

35. Dionne CE, Dunn KM, Croft PR. Does back pain prevalence really decrease with increasing age? A systematic review. Age Ageing. 2006;35(3):229-234. doi:10.1093/ageing/afj055

36. Shiri R, Karppinen J, Leino-Arjas P, Solovieva S, Viikari-Juntura E. The association between obesity and low back pain: a meta-analysis. Am J Epidemiol. 2010;171(2):135-154. doi:10.1093/aje/kwp356

37. Zhang TT, Liu Z, Liu YL, Zhao JJ, Liu DW, Tian QB. Obesity as a risk factor for low back pain: a meta-analysis. Clin Spine Surg. 2018;31(1):22-27. doi:10.1097/BSD.0000000000000468

38. Kauppila LI. Atherosclerosis and disc degeneration/low-back pain-a systematic review. Eur J Vasc Endovasc Surg. 2009;37(6):661-670. doi:10.1016/j.ejvs.2009.02.006
39. Tamura Y. Ectopic fat, insulin resistance and metabolic disease in non-obese Asians: investigating metabolic gradation. Endocr J. 2019;66(1):1-9. doi:10.1507/endocrj.EJ18-0435

40. Velten J, Lavallee KL, Scholten S, et al. Lifestyle choices and mental health: a representative population survey. BMC Psychol. 2014;2 (1):58. doi:10.1186/s40359-014-0055-y

41. Walsh R. Lifestyle and mental health. Am Psychol. 2011;66 (7):579-592. doi:10.1037/a0021769

42. Yokokawa H, Fukuda H, Yuasa M, Sanada H, Hisaoka T, Naito T. Association between health literacy and metabolic syndrome or healthy lifestyle characteristics among community-dwelling Japanese people. Diabetol Metab Syndr. 2016;8(1):30. doi:10.1186/ s13098-016-0142-8

43. Edward J, Carreon LY, Williams MV, Glassman S, Li J. The importance and impact of patients' health literacy on low back pain management: a systematic review of literature. Spine J. 2018;18 (2):370-376. doi:10.1016/j.spinee.2017.09.005

44. Suka M. Cost-effectiveness of preventive interventions against back pain in Japanese health examinees. Health Eval Promot. 2009;36 (6):445-451

\section{Publish your work in this journal}

The Journal of Pain Research is an international, peer reviewed, open access, online journal that welcomes laboratory and clinical findings in the fields of pain research and the prevention and management of pain. Original research, reviews, symposium reports, hypothesis formation and commentaries are all considered for publication. The manuscript management system is completely online and includes a very quick and fair peer-review system, which is all easy to use. Visit http:// www.dovepress.com/testimonials.php to read real quotes from published authors. 